\title{
In Defense of the Commons: Young Children Negatively Evaluate and Sanction Free Riders
}

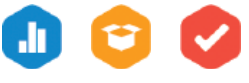

\author{
Fan Yang ${ }^{1}$, You-Jung Choi ${ }^{2}$, Antonia Misch ${ }^{1,3}$, Xin Yang ${ }^{1}$, and \\ Yarrow Dunham ${ }^{1}$ \\ ${ }^{1}$ Department of Psychology, Yale University; ${ }^{2}$ Department of Psychology, Harvard University; \\ and ${ }^{3}$ Department of Psychology, Ludwig Maximilian University
}

\begin{abstract}
Human flourishing depends on individuals paying costs to contribute to the common good, but such arrangements are vulnerable to free riding, in which individuals benefit from others' contributions without paying costs themselves. Systems of tracking and sanctioning free riders can stabilize cooperation, but the origin of such tendencies is not well understood. Here, we provide evidence that children as young as 4 years old negatively evaluate and sanction free riders. Across six studies, we showed that these tendencies are robust, large in magnitude, tuned to intentional rather than unintentional noncontribution, and generally consistent across third- and first-party cases. Further, these effects cannot be accounted for by factors that frequently co-occur with free riding, such as nonconforming behaviors or the costs that free riding imposes on the group. Our findings demonstrate that from early in life, children both hold and enforce a normative expectation that individuals are intrinsically obligated to contribute to the common good.
\end{abstract}

\section{Keywords}

free riding, common good, norm enforcement, moral development, cooperation, open data, open materials, preregistered

Received 11/13/17; Revision accepted 4/27/18

From mutual defense and food sharing through modern activities such as paying taxes, contributing to common goods that are mutually beneficial is at the heart of human sociality. However, contributions to common goods frequently come at a personal cost to the contributor, creating an incentive for the individual to reap the benefits of group living without paying the costs, that is, to "free ride" on the actions of others. If common, free riding leads to the collapse of multiparty cooperative activities (e.g., Fehr \& Fischbacher, 2003; Fehr \& Gächter, 2000). Thus, solving the free-rider problem is a necessary precursor to successful group living.

While cooperation is present in many species, humans display an unusual tendency to engage in cooperation with genetically unrelated others (Boyd \& Richerson, 2009). Indeed, human cooperation goes beyond simple reciprocal dyadic interactions, extending to complex forms of mutuality in which multiple parties cooperate to achieve shared goals. However, multiparty cooperation may be especially susceptible to free riding because of the increased demands of tracking multiple parties, and some researchers have suggested that humans have evolved psychological mechanisms focusing on detecting free riders, sometimes called cheater detection (Tooby, Cosmides, \& Price, 2006). Indeed, only humans appear to spontaneously track and detect free riders (Delton, Cosmides, Guemo, Robertson, \& Tooby, 2012), while also negatively evaluating and punishing them in the absence of tangible benefits (Fehr \& Gächter, 2000; Masclet, Noussair, Tucker, \& Villeval,

Corresponding Author:

Fan Yang, Yale University, Department of Psychology, 2 Hillhouse Ave., New Haven, CT 06511

E-mail: fan.yang@yale.edu 
2003; Price, 2005, 2006a, 2006b; Price, Cosmides, \& Tooby, 2002).

Where does our tendency to sanction free riders come from, and how deeply ingrained is it? Findings with adults are consistent with an evolved psychological tendency to track and punish free riders, but given the widespread prevalence of social norms against free riding, it is also plausible that these behaviors emerge only as older children internalize cooperative norms embedded in the larger community (House et al., 2013). Thus, developmental data are a relevant source of evidence: An evolved tendency to track and punish free riders might predict that it should be present among children even prior to entrance into formal schooling, and even prior to the ages at which they are expected to contribute to public goods. Here, we exploited the strength of a developmental approach to study the origin and development of the negative evaluation and sanctioning of free riders to multiparty cooperation.

Some past work has examined questions relevant to free riding in developmental populations. Most has examined children's reactions in first-party settings when their own outcomes are affected by free riders (Alencar, de Oliveira Siqueira, \& Yamamoto, 2008; Harbaugh \& Krause, 2000; Vogelsang, Jensen, Kirschner, Tennie, \& Tomasello, 2014). This work has shown that children's contributions decline when they discover the presence of free riders (Alencar et al., 2008; Harbaugh \& Krause, 2000) and that they share fewer resources with partners who have previously rejected collaboration (Melis, Altrichter, \& Tomasello, 2013), patterns familiar from adult work (Fischbacher, Gächter, \& Fehr, 2001; Keser \& Van Winden, 2000). Thus, children are sensitive to free riding when they are directly harmed by it. However, the first-party nature of these studies entails that children's behavior could be driven by the desire to retaliate against people who have negatively impacted their payoffs rather than an aversion to free riding per se. The more critical test comes from contexts in which children's outcomes are unaffected by free riding. In such cases, do children still negatively evaluate and sanction free riding?

Children are sensitive to some types of moral and social norms even when their own interests are not at stake. For example, they expect in-group loyalty in some contexts (Jin \& Baillargeon, 2017; Yuill \& Perner, 1988 ) and actively protest against transgressions involving physical harm (Kenward \& Dahl, 2011; Kenward \& Östh, 2012), property rights (Riedl, Jensen, Call, \& Tomasello, 2015; Rossano, Rakoczy, \& Tomasello, 2011; Vaish, Missana, \& Tomasello, 2011), resource distributions (Jordan, McAuliffe, \& Warneken, 2014; McAuliffe, Jordan, \& Warneken, 2015), and game rules (Rakoczy, Brosche, Warneken, \& Tomasello, 2009; Rakoczy,
Warneken, \& Tomasello, 2008; Schmidt, Rakoczy, \& Tomasello, 2012; Wyman, Rakoczy, \& Tomasello, 2009). However, free riding differs from these violations in several important respects. For example, unlike typical moral transgressions involving interpersonal harm with an easily identifiable victim (Gray, Young, \& Waytz, 2012), free riding often has consequences that are distributed across a group such that they lack immediately salient victims. And unlike violations of clear normative rules, free riding appears to violate a tacit rather than explicit norm of multiparty cooperation. Little is known about when this type of norm is appreciated, let alone enforced. Finally, typical instances of free riding have a number of dissociable properties (discussed below), and little work has examined which of these is most impactful in driving emerging judgments.

Thus, in the present research, we explored the origin of expectations of contributions to the common good by examining the following questions. First, do children negatively evaluate or sanction free riders in group situations when their own self-interest is not at stake? We examined this question both when children were thirdparty observers (Studies 1-5) and when they were firstparty players (Study 6). Second, what drives children's response to free riders? Free riders can differ from contributors in several dissociable ways. Generally, free riders intend to exploit the group, their actions impact the group's payoff as a whole, they receive an undeserved reward by benefitting from the work of other people, and by virtue of deviating from a norm of contribution, free riders are usually nonconformists. Which of these factors drives judgments of free riders? Third, how do observed results change across development? For example, do they grow stronger with age, a pattern that would be consistent with an account in which socialization drives sanctioning of free riders?

Across six studies, we show that children between the ages of 4 and 10 years negatively evaluate and punish free riders compared with contributors even if their own interests are not at stake, both as third-party observers and as first-party players; their evaluations are sensitive to whether or not the free riding occurs voluntarily; and their evaluations hold even when free riding does not impose costs on the group and when free riding is not an instance of nonconformity. Contrary to the prediction that would follow from a socialization account, these effects were generally stronger in younger than older children. These studies provide evidence that young children have a strong normative expectation of collaborative group behavior and are willing to pay costs to enforce it, and thus from early in development take costly action to facilitate multiparty cooperation even when their own payoffs are not involved. 


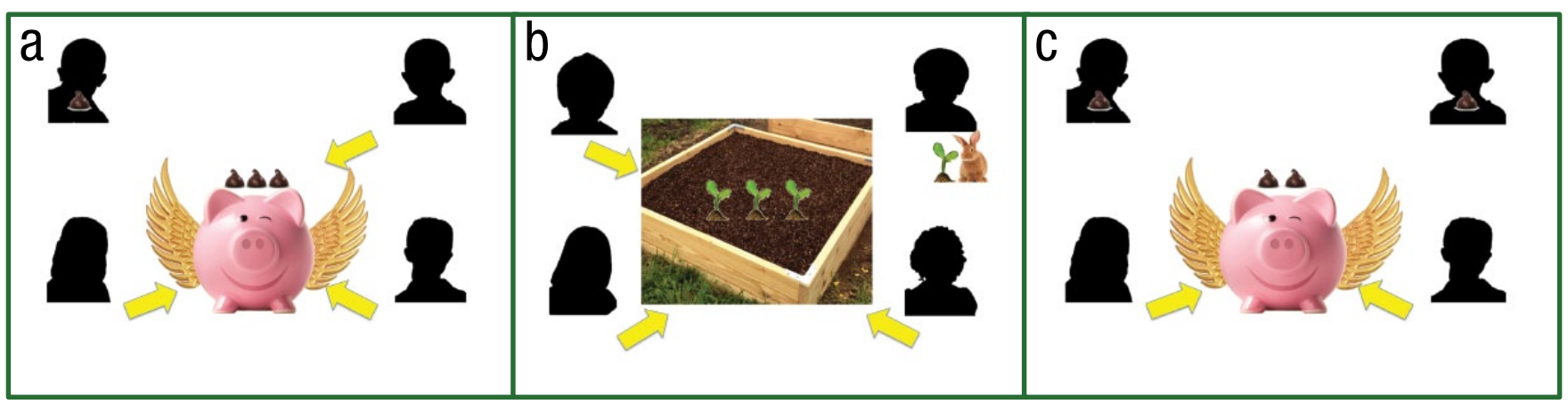

Fig. 1. Illustrations of the stories depicted to participants in the (a) intentional-free-riding condition with one free rider (Studies $1-3$ and 5), (b) unintentional-free-riding condition with one free rider (Studies 1 and 2), and (c) intentional-free-riding condition with two free riders (Study 4). The group in each story had four members; the arrows in each panel indicate which group members put their chocolate in the piggy bank (a, c) or placed their plant in the garden (b). In (a) and (c), the members who kept the chocolate (free riders) did so voluntarily, whereas in (b), the member who did not put the plant in the garden refrained from doing so because a pet rabbit ate the plant (as indicated here) or because of an injury (not shown).

\section{Study 1}

Our first study established a procedure to evaluate third-party free riders in children while testing whether such evaluations were sensitive to the role of intentionality, which is essential to adult conceptions of morality in general (Gray et al., 2012) and free riding in particular (Delton et al., 2012).

\section{Metbod}

Participants. We focused on children between the ages of 6 to 10 years because past work has established that children in this age group show an understanding of group-cooperative settings and are sensitive to noncontribution in public-goods games when their payoffs are involved (Alencar et al., 2008; Harbaugh \& Krause, 2000). Studies 1 and 2 were exploratory and conducted on the basis of past work on third-party punishment as well as our lab default for new developmental work of 32 participants per cell. We recruited 32 children 6 to 10 years old $(M=8.69, S D=1.46 ; 17$ female $)$. Data collection was stopped when the predetermined sample size was met. Children in this and all following studies were recruited and tested in a campus lab, at schools, and at a local museum; effects did not differ between testing locations for all the studies, and so this factor is not discussed further. The majority of children in this study and in following studies were from middle-class families and of European American ethnicity (> 75\%). There were no differences between demographic information across the studies, so we do not repeat this information in following studies. All studies were approved by the Yale University Institutional Review Board. Written parental consent was obtained in advance of all testing; children also provided verbal assent prior to beginning the procedures.
Design and procedure. We presented each participant with two scenarios in which a four-member group could obtain a large reward if all four members contributed to a collective goal or a smaller reward if only three members contributed. The scenarios were described verbally by the experimenter and depicted through pictures on a laptop display. One scenario involved a magic piggy bank modeled after a public-goods game in which placing chocolates in a piggy bank would lead to the appearance of a cake that was then shared among the group. The other scenario involved a more naturalistic gardening setting in which placing plants in a garden produced tomatoes. Each participant heard both scenarios, one involving an unwilling free rider (intentional-free-riding condition) and one involving a willing but unable free rider (unintentional-free-riding condition). Key conditions and scenes are represented in Figure 1. To establish a modicum of generality, we investigated two types of free riding (withholding of a valuable resource versus withholding of effort). Half of the participants heard a donation version of the story (i.e., donate chocolate to the piggy bank and donate plants to the garden), and the other half of participants heard an effort version (i.e., clean the dirty piggy bank and grow the tomatoes). The type of free riding (withholding of resources versus effort) was thus manipulated between subjects, and across subjects, all pairings among scenario, type of free riding, and intentionality were included.

During testing, children were first introduced to the groups and told how the piggy bank or garden worked in terms of the rewards (i.e., get a bigger cake or basket of tomatoes with contributions from four members vs. three members). As a memory check, children were asked at the end of this familiarization phase about which reward the group would get if three versus four members contributed and all children answered the questions correctly. 
After familiarization, in the intentional-free-riding condition (Fig. 1a), children were shown through animations that the free rider kept the resources for themselves or made no actions. In the unintentional-free-riding condition (Fig. $1 \mathrm{~b})$, the free riders wanted to donate or make an effort to the group, but their resource was eaten by a pet (donation version) or they could not do the work because of an injury (effort version). In both conditions, the contributors put in the resources or made the actions. Finally, children were shown that the group got the second-best reward, and each child target got a small but equal share of the group reward. Children were asked to rate the free rider and one of the contributors on a 4-point scale indicating (a) how good or bad each character was (judgment question) and (b) how much they liked or disliked each character (preference question). At the end of the session, children were asked two memory questions about (a) whether the group received the bigger or the smaller reward (outcome question) and (b) whether three or four people contributed to the group (action question).

\section{Results}

All children answered the memory questions correctly. Children's judgment and preference ratings ranged from
1 (most negative) to 4 (most positive). Preliminary results indicated no differences between the two types of scenario (piggy bank vs. gardening), the type of free riding (effort vs. donation), or the type of question (judgment vs. preference), so we collapsed across these factors in primary analyses. We used children's judgment and preference ratings as indicators for evaluation ratings and analyzed data via mixed linear models predicting children's ratings as a function of target (dummy coded; free rider vs. contributor), intentionality (dummy coded; whether the scenario involved intentional vs. unintentional free riding), child age, and the interactions among them, with a random intercept for participant. Data and code to replicate all analyses reported in this article are available at https://osf.io/g8xyt/.

We found effects of target $(\beta=1.79,95 \%$ confidence interval, $C I=[1.58,2.01])$, intentionality $(\beta=0.94,95 \%$ $\mathrm{CI}=[0.72,1.15])$, and age $(\beta=0.01,95 \% \mathrm{CI}=[0.003$, $0.02])$, as well as an interaction between target and intentionality $(\beta=-1.0,95 \% \mathrm{CI}=[-1.31,-0.69]$; Fig, $2 \mathrm{a})$. Children's evaluations of free riders $(M=2.53)$ were considerably more negative than those of contributors $(M=$ 3.83; $d=1.62$ ), and more negative for intentional free riders $(M=2.06)$ than for unintentional free riders $(M=$ 3.00; $d=1.04)$, though they still evaluated unintentional a

\section{6- to 10 -Year-Olds}

Intentional Free Riding Unintentional Free Riding

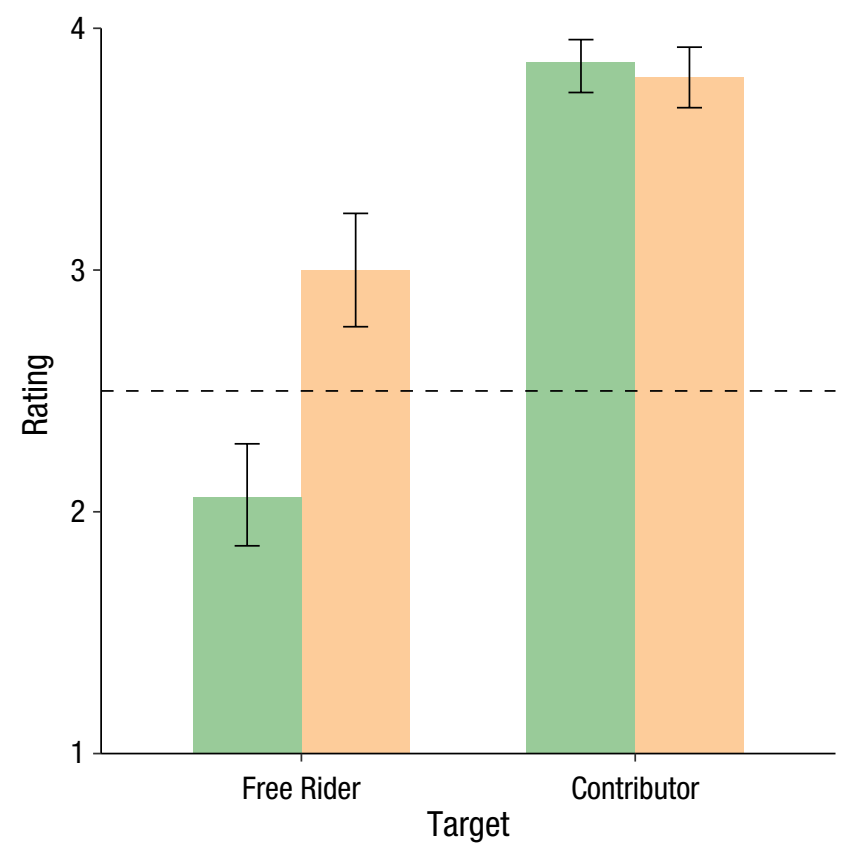

b

\section{4- to 5-Year-Olds}

Intentional Free Riding Unintentional Free Riding

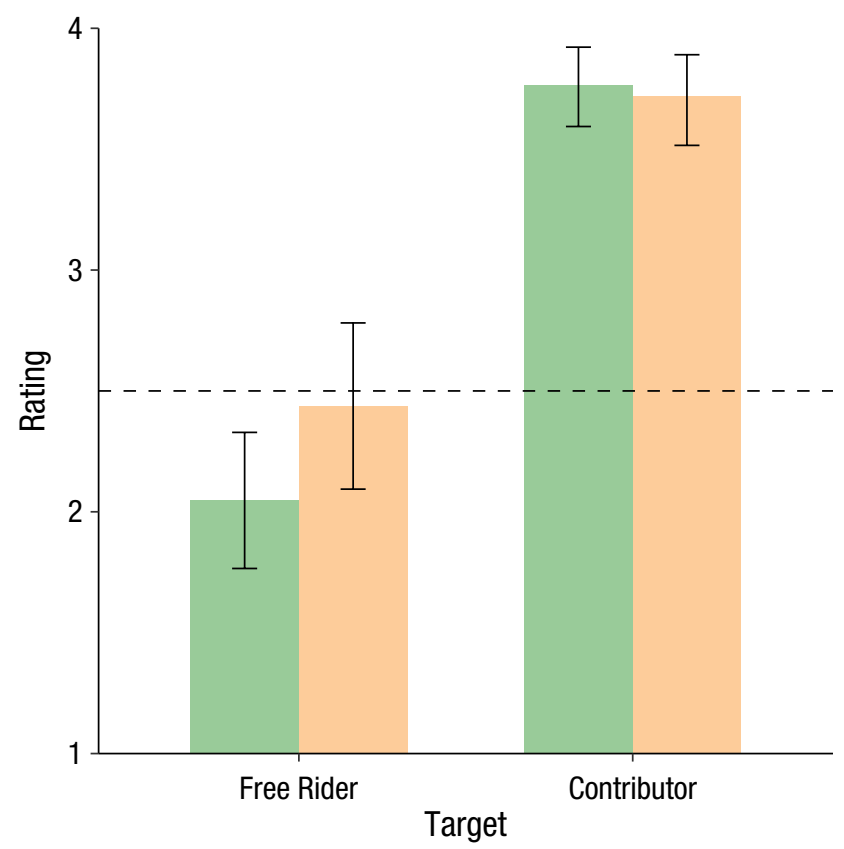

Fig. 2. Children's evaluations of free riders and contributors in the intentional-free-riding and unintentional-free-riding conditions in (a) Study $1(N=32)$ and (b) Study $2(N=32)$. Error bars represent bootstrapped $95 \%$ confidence intervals. On the $y$-axes, 1 equals most negative, and 4 equals most positive. Dashed lines indicate the level of chance response. 
free riders more negatively than contributors $(d=1.08)$. Evaluations of contributors did not vary as a function of whether the free riding was intentional or unintentional. Finally, evaluations were also somewhat more positive with increasing age, although even the older children's evaluations were still negative in nature. Thus, across this age range, children negatively evaluate free riders and are sensitive to the intentions that drove them. In the next study, we explored whether this tendency emerged in even younger children who have not started formal schooling, have more limited group experiences, and are generally not yet expected to contribute to common goods.

\section{Study 2 \\ Metbod}

We tested 32 children 4 to 5 years old $(M=4.93, S D=$ $0.60,16$ female) using the same testing materials and followed the same procedure as in Study 1 .

\section{Results}

The majority of the children (> 95\%) answered the memory questions correctly. We carried out the same analysis as in Study 1 and observed effects for target $(\beta=1.72$, $95 \% \mathrm{CI}=[1.44,2.00])$ and intentionality $(\beta=0.39,95 \%$ $\mathrm{CI}=[0.11,0.67])$ and an interaction between target and intentionality $(\beta=-0.44,95 \% \mathrm{CI}=[-0.83,-0.04]$; Fig. $2 \mathrm{~b})$. An additional interaction between target and age $(\beta=-0.03,95 \% \mathrm{CI}=[-0.06,-0.002])$ suggested that the difference between free riders and contributors declined somewhat over this age range. Much like older children, preschoolers rated contributors $(M=3.74)$ more positively than the free riders $(M=2.24 ; d=1.40)$ and distinguished intentional ( $M=2.05$ ) from unintentional $(M=2.44)$ free riders $(d=0.30)$.

Comparing results from Study 1 and Study 2 in a single model confirmed effects of target $(\beta=1.76,95 \%$ $\mathrm{CI}=[1.58,1.93])$ and intentionality $(\beta=0.66,95 \% \mathrm{CI}=$ $[0.49,0.84])$, as well as the interaction between target and intentionality $(\beta=-0.72,95 \% \mathrm{CI}=[-0.97,-0.47])$. Including this wider age range also revealed an interaction between intentionality and age $(\beta=0.01,95 \%$ $\mathrm{CI}=[0.006,0.02])$ and $\mathrm{a}$ three-way interaction among target, intentionality, and age $(\beta=-0.01,95 \% \mathrm{CI}=$ $[-0.02,-0.003])$ driven by older children rating unintentional free riders more positively than younger children did, demonstrating an age-related increase in the influence of intentionality on judgments of free riders. More broadly, however, the findings from Studies 1 and 2 demonstrate that children negatively evaluate free riders and especially intentional free riders by age 4 .

\section{Study 3}

In Studies 1 and 2, children negatively evaluated free riders, but it was not clear whether this was due to the act of free riding per se or because free riding inflicted a negative outcome on the group. Existing literature suggests that children sometimes overweight outcomes in moral judgments; (Cushman, Sheketoff, Wharton, \& Carey, 2013; Killen, Mulvey, Richardson, Jampol, \& Woodward, 2011; Yuill \& Perner, 1988; Zelazo, Helwig, \& Lau, 1996), so we next investigated whether judgments of free riders remained negative when free riding did not affect the group's outcome.

\section{Method}

Participants. The presence of clear and strong effects in the first two studies led us to retain a total sample size of 32 for this and the subsequent studies. We recruited 32 children to participate in this study (14 female), 16 of whom were 4 to 5 years old $(M=4.76, S D=0.54)$, and 16 of whom were 9 to 10 years old $(M=9.97, S D=0.66)$.

Procedure. To examine whether children's negative reactions to free riding were based on the negative outcomes caused by free riders, we presented children with a new no-group-impact scenario in which the free rider did not bring about any negative consequences to the group outcome. In this story, children were shown during the familiarization phase that if three members donate, the group reward obtained would be bigger than if two members contributed and still bigger than if one member contributed, but the reward for contributions from three versus four members was the same. They were also shown that in the end, despite the noncontribution of the free rider, the group still got the biggest possible reward that was then shared equally with all involved parties including the free rider. As a comparison, each child also heard the intentional-free-riding story from Studies 1 and 2. Children made the same judgment and preference ratings for the free riders and contributors after each story, followed by the two memory questions (which reward the group obtained and how many members contributed).

\section{Results}

The study design and analysis plan were preregistered at https://aspredicted.org/uv6ha.pdf (note that Study 3 was preregistered as Study 2). All older children and the majority of the younger children (> 80\%) answered the memory questions correctly; excluding the children who failed the memory questions did not change the results, so they were included in the analyses. Following similar coding and analyses in Studies 1 and 2, we 
a

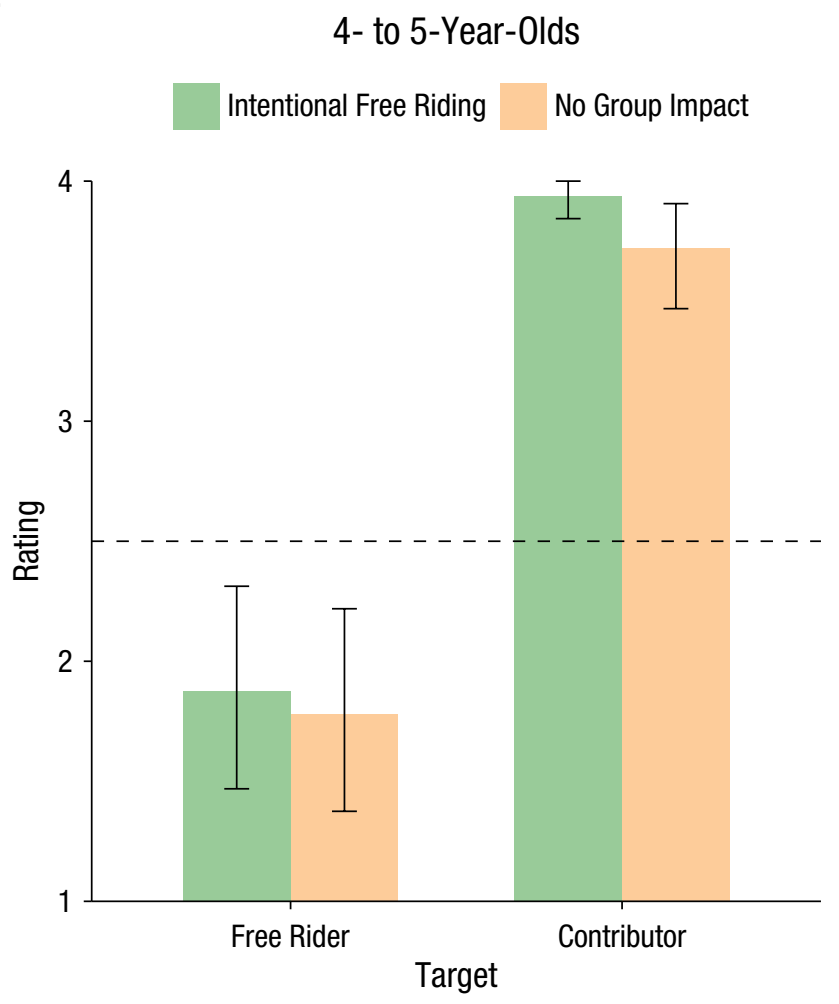

b

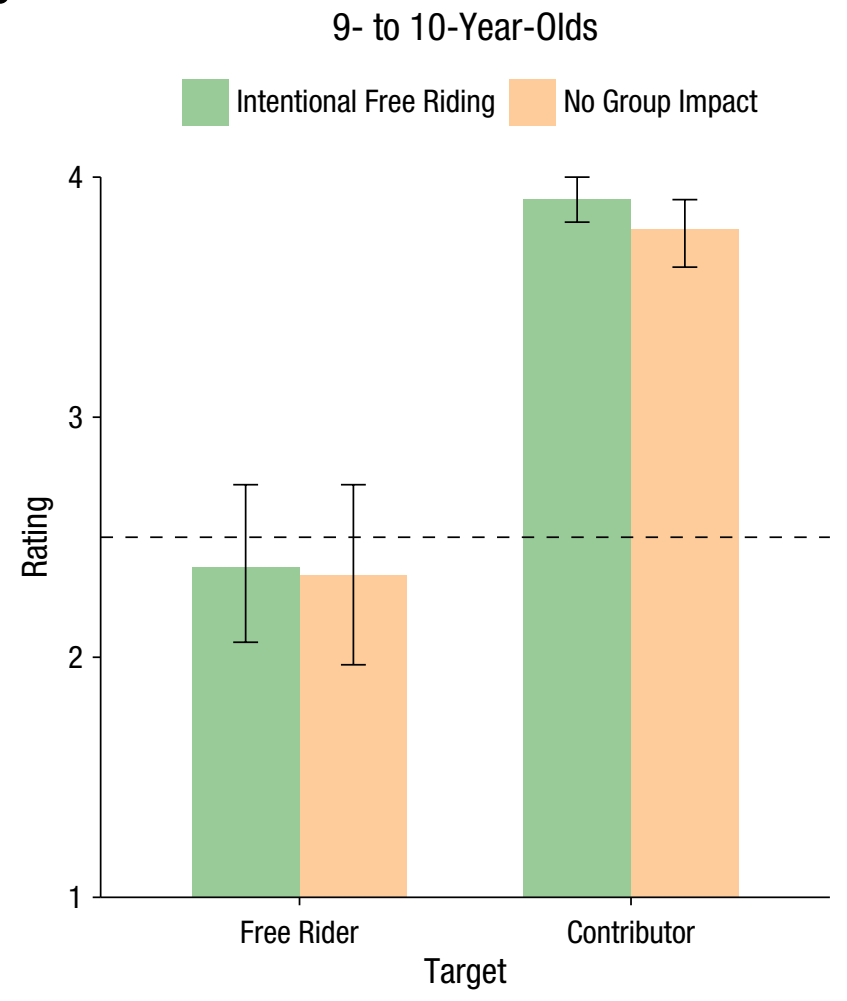

Fig. 3. Children's evaluations of free riders and contributors in the intentional-free-riding and no-group-impact conditions in Study 3 , separately for (a) 4- to 5-year-olds $(n=16)$ and (b) 9- to 10-year-olds $(n=16)$. Error bars represent bootstrapped $95 \%$ confidence intervals. On the $y$-axes, 1 equals most negative, and 4 equals most positive. Dashed lines indicate the level of chance response.

analyzed data via mixed linear models predicting children's evaluation ratings as a function of target (free rider vs. contributor), impact (dummy coded; whether the group obtained the biggest outcome vs. the smaller outcome), child age, and the interactions among them, with a random intercept for participant. We found effects for target $(\beta=1.74,95 \% \mathrm{CI}=[1.57,1.92])$, indicating that contributors were rated more positively than free riders, and age group $(\beta=0.53,95 \% \mathrm{CI}=[0.11$, $0.95]$ ), indicating that older children provided somewhat more positive ratings than younger children. These effects were qualified by an interaction between target and age group $(\beta=-0.52,95 \% \mathrm{CI}=[-0.86$, $-0.17])$, indicating that the difference between ratings of contributors and free riders was somewhat greater for younger children (Fig. 3). We did not find an effect of impact $(\beta=0.12,95 \% \mathrm{CI}=[-0.06,0.29])$ or interactions with this term. Children's ratings for the free riders were similar in the no-group-impact condition $(M=$ 2.06) and in the intentional-free-riding condition $(M=$ 2.13). These results indicate that children evaluate intentional free riding as bad in general even when it does not inflict an appreciable loss on the group.

\section{Study 4}

Many real-world instances of free riding are also instances of nonconformity, in that contribution is generally the norm. Young children expect other people to conform (Corriveau \& Harris, 2010; Haun \& Tomasello, 2011; Walker \& Andrade, 1996) and sometimes dislike nonconformers (Stoddart \& Turiel, 1985; Toomey, Card, \& Casper, 2014). Study 4 explored whether aversion to nonconformity drives children's negative evaluations of free riders.

\section{Method}

Participants. Participants were 32 children (15 female), 16 of whom were 4 to 5 years old $(M=4.93, S D=0.48)$, and 16 of whom were 9 to 10 years old $(M=10.16, S D=0.74)$.

Procedure. To explore whether an aversion to nonconformity was underlying children's responses to free riders, we presented each child with a new two-free-riders scenario based on the intentional-free-riding story from Study 1 but in which two characters put in the resources 
(i.e., contributed) whereas the other two characters did not (i.e., free rode; Fig. 1c.) This meant that within the context of the scenario, free riding was no longer a minority behavior and therefore not a meaningful instance of nonconformity. The order in which children heard about free riding versus contributing actions was counterbalanced, so that half of the participants were introduced to the free riders first, and the other half of the participants were introduced to the contributors first. As before, children evaluated one of the free riders and one of the contributors in a counterbalanced order and answered two memory questions (i.e., outcome and action questions) in the end.

\section{Results}

All children except two 4-year-old children answered the memory questions correctly; excluding the two 4-year-olds did not change the results, so they were included. As in previous studies, we used target (free rider vs. contributor), child age, and their interaction to predict children's evaluation ratings in a mixed linear model. Replicating the previous results, we found that children in both age groups evaluated the free rider more negatively than the contributor even when there were two free riders $(\beta=1.66,95 \% \mathrm{CI}=[1.39,1.92])$; there was no effect of age group $(\beta=0.16,95 \% \mathrm{CI}=$ $[-0.21,0.52]$; Fig. 4). A direct comparison with the findings for the intentional-free-riding condition in Study 3 revealed no significant effect of condition in predicting children's evaluations ( $\beta=-0.01,95 \% \mathrm{CI}=[-0.54,0.51])$ whether the free riding was $(M=2.13)$ or was not $(M=$ 2.11) an instance of nonconformity. Thus, children's negative evaluations of free riders cannot be accounted for by the nonconformity of free riding.

\section{Study 5}

Study 5 focused on children's behavior toward free riders, in particular whether they differentially punish and reward free riders compared with contributors. A secondary question was whether children dislike free riders because they receive an undeserved reward, which we tested by omitting information about how rewards were ultimately distributed.

\section{Method}

Participants. Participants were 32 children (13 female), 16 of whom were 4 to 5 years old $(M=4.77, S D=0.53)$, and 16 of whom were 9 to 10 years old $(M=9.95, S D=0.76)$.

Procedure. Each child heard the same intentional-freeriding story as in previous studies and a no-outcome
4- to 5-Year-0lds 9- to 10-Year-Olds

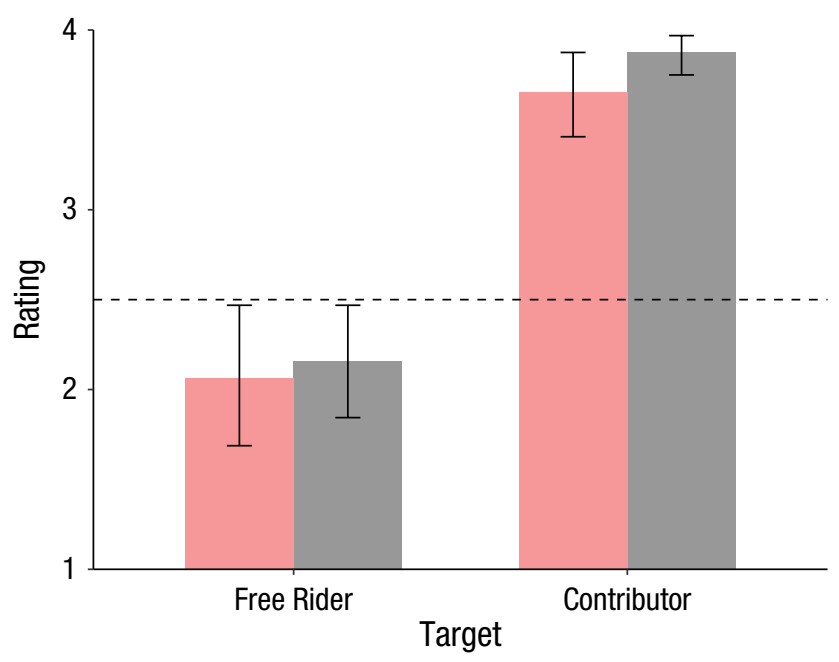

Fig. 4. Children's evaluations of free riders and contributors in the two-free-riders condition in Study 4, separately for 4- to 5-yearolds $(n=16)$ and 9- to 10-year-olds $(n=16)$. Error bars represent bootstrapped $95 \%$ confidence intervals. On the $y$-axis, 1 equals most negative, and 4 equals most positive. The dashed line indicates the level of chance response.

story that was identical except that all information about the effect of free riding on payoffs was omitted. Participants also completed additional punishment and reward tasks. Immediately after children heard each story, we asked them to rank three types of stickers in terms of their preferences and gave them three stickers of their favorite type. After the judgment and preference ratings, children were presented with a noncostly punishment task in which they were given the opportunity to take away a resource from a character. Then, regardless of children's responses, as a measure of costly punishment, they were given the opportunity to sacrifice a desirable sticker they would otherwise be able to take home to inflict a further punishment on a character.

After completing the punishment tasks, children were presented with two reward tasks. Children were first told that the group had obtained some candies as a reward for their work. In the reward-decision task, children were asked whether they would like to reward each character by allocating some candies. Then regardless of their responses, in the reward-behavior task, children were shown three real candies and were asked to put the candies that they wanted and did not want the character to receive in two separate boxes. As in previous studies, at the end of the session, children were asked control questions about how many people contributed to the group (action question) as well as what reward the group actually got in the end (the biggest vs. the smaller reward). Children answered these questions correctly at an overwhelmingly high 
rate (>95\%), and their responses were not correlated with their responses to the test questions.

The procedure for the no-outcome condition was the same, except that children were shown only the group setting and the behaviors of the characters, with no familiarization about how different numbers of contributors would affect the group reward or what reward the group or the individuals obtained in the end. The order of the stories was counterbalanced in each study. We also counterbalanced the order in which children were asked to rate free riders versus contributors.

\section{Results}

Beginning with the evaluation items, we carried out similar analyses as in previous studies, analyzing data via mixed linear models predicting children's evaluation ratings as a function of target (free rider vs. contributor), condition (dummy coded; whether group and individual outcomes were revealed vs. not revealed), child age, and the interactions among them, with a random intercept for participant. We again found effects for target $(\beta=1.96,95 \% \mathrm{CI}=[1.81,2.11])$, with contributors rated more positively than free riders, and for age group $(\beta=0.78,95 \% \mathrm{CI}=[0.42,1.14])$, with older children providing somewhat more positive ratings. These effects were qualified by an interaction between target and age group $(\beta=-0.86,95 \% \mathrm{CI}=[-1.16,-0.56])$; specifically, the difference between ratings of contributors and free riders was somewhat higher in younger children (Fig. 5). We did not find evidence for an effect of condition $(\beta=-0.04,95 \% \mathrm{CI}=[-0.19,0.11])$. These findings suggest that children viewed free riding itself as a moral wrong and were not merely reacting to seeing a noncooperator receive an undeserved reward.

We analyzed punishment behavior in a mixed logistic regression with trials nested within participants. Because some models with higher-order interaction terms failed to converge, we employed alternative optimizers provided by the optimx package (Version 2013.8.7) in $\mathrm{R}$ but verified all final models with the default optimizers (which did converge) as well as with linear probability models; all approaches provided qualitatively similar patterns of results. Children's reward behaviors ranged from 0 to 3 (number of candies donated) and were analyzed in a linear model parallel to those described for evaluations above. This analysis revealed effects for target $(\beta=-4.35,95 \%$

\section{a}

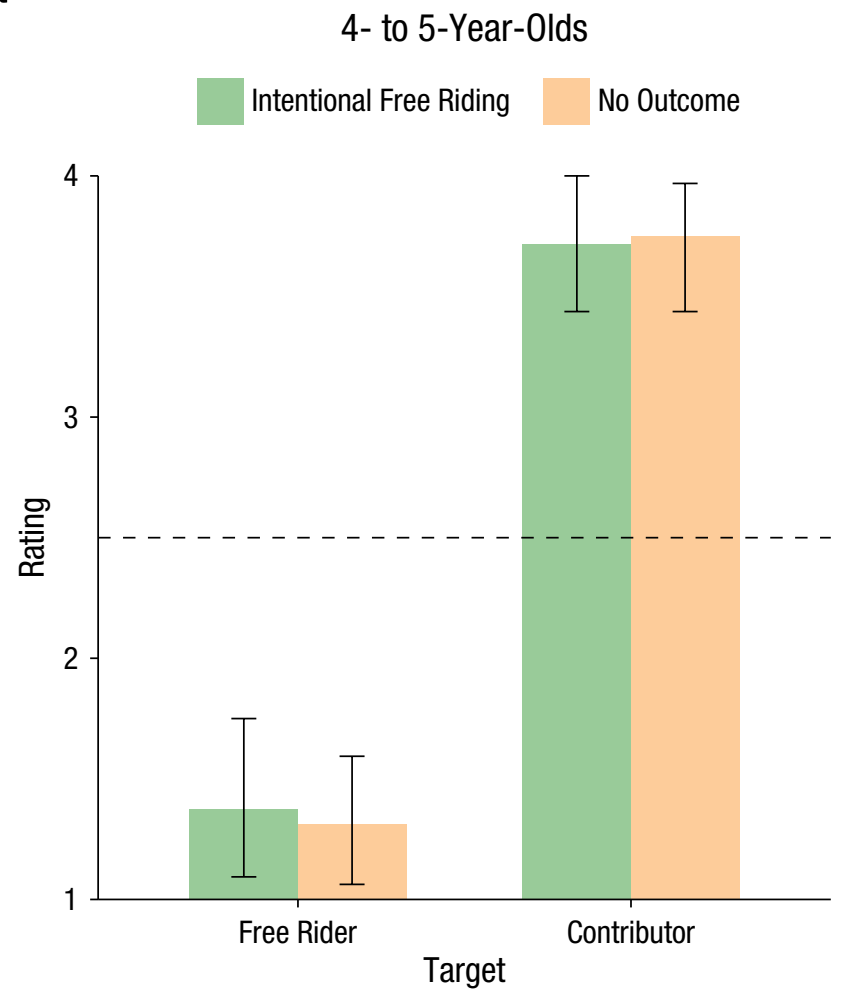

b

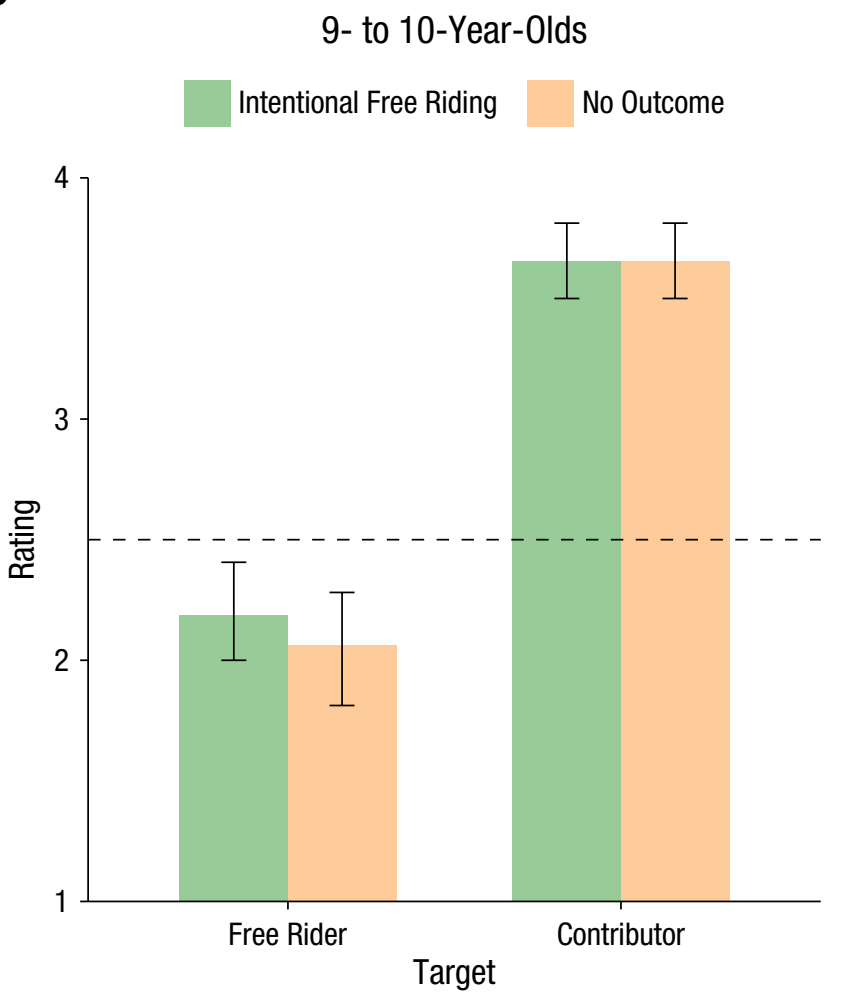

Fig. 5. Children's evaluations of free riders and contributors in the intentional-free-riding and no-outcome conditions of Study 5 , separately for (a) 4- to 5-year-olds $(n=16)$ and (b) 9 - to 10-year-olds $(n=16)$. Error bars represent bootstrapped $95 \%$ confidence intervals. On the $y$-axes, 1 equals most negative, and 4 equals most positive. Dashed lines indicate the level of chance response. 


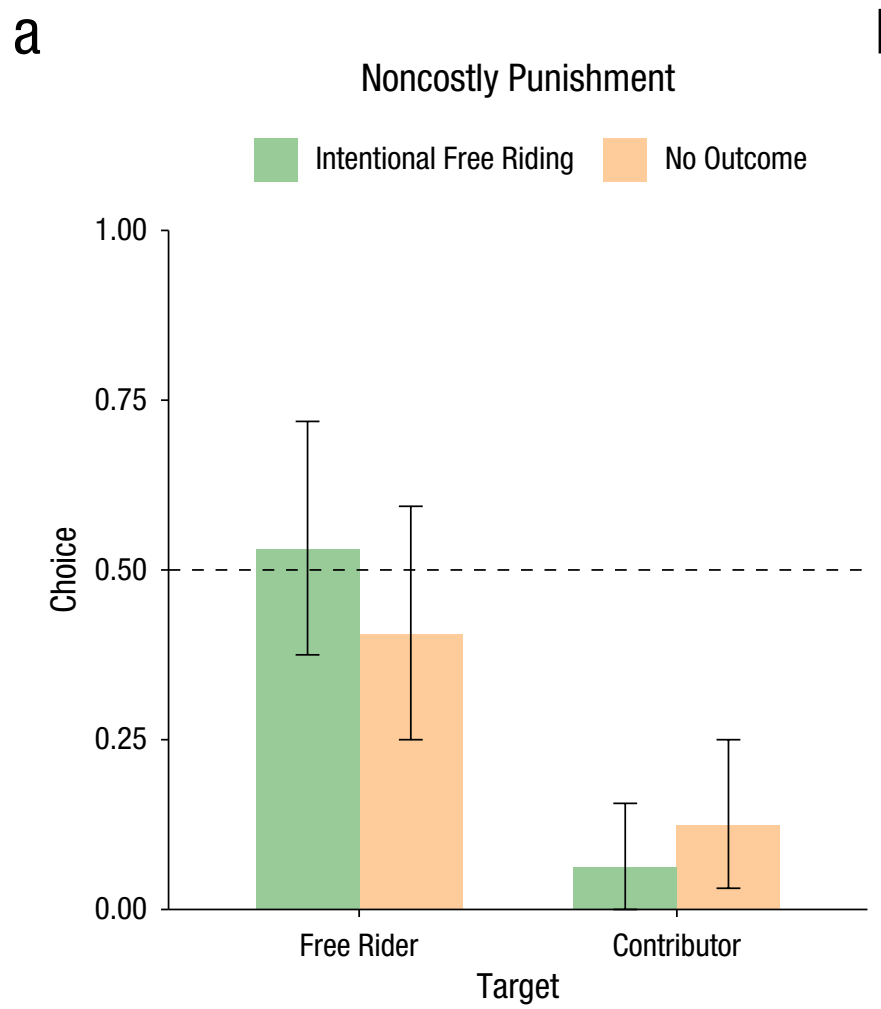

b

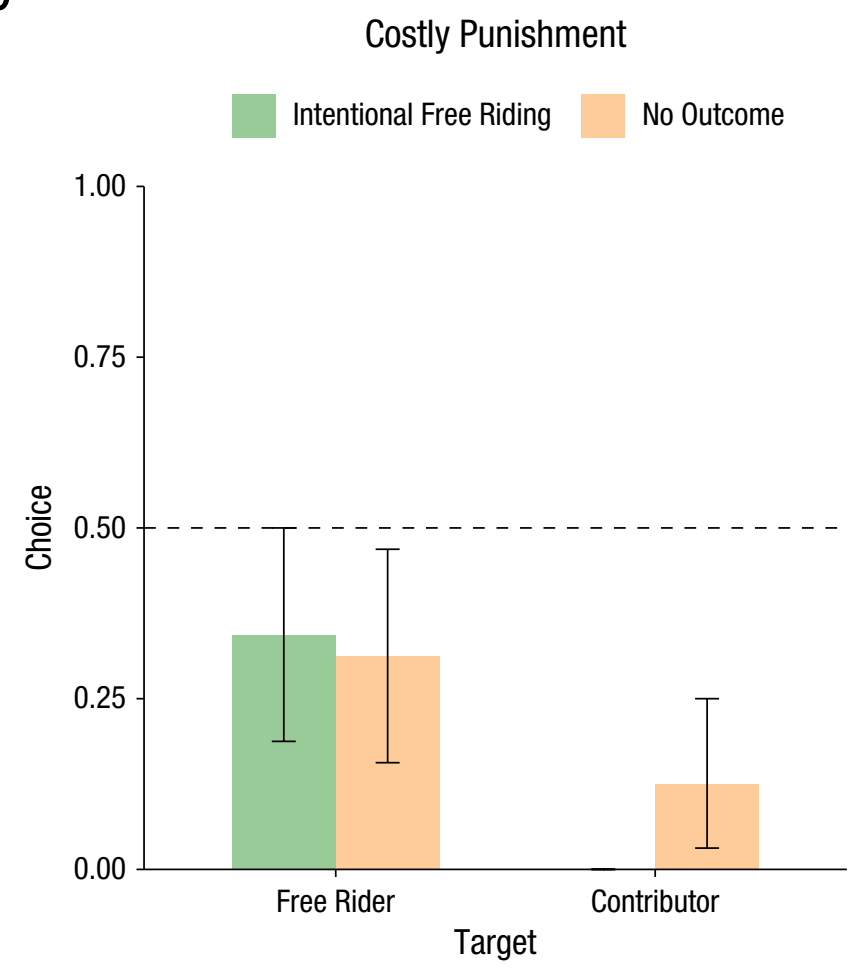

Fig. 6. Children's (a) noncostly punishment and (b) costly punishment of free riders and contributors in the intentional-free-riding and no-outcome conditions of Study 5 (16 children 4-5 years old and 16 children 9-10 years old). Error bars represent bootstrapped 95\% confidence intervals. On the $y$-axes, 0 indicates a decision not to punish, and 1 indicates a decision to punish. Dashed lines indicate the level of chance response. Note that the mean for contributors in the intentional-free-riding condition was 0.

$\mathrm{CI}=[-6.46,-2.79], \mathrm{OR}=0.01)$, with much greater punishment of free riders than contributors, and type of punishment (noncostly versus costly; $\beta=-0.85,95 \%$ $\mathrm{CI}=[-1.68,-0.07], \mathrm{OR}=0.42)$, with more noncostly than costly punishment (see Fig. 6). We did not find an effect of age $(\beta=-0.21,95 \% \mathrm{CI}=[-1.95,1.51], \mathrm{OR}=$ $0.81)$ or condition $(\beta=-0.53,95 \% \mathrm{CI}=[-1.47,0.37]$, $O R=0.59)$. Turning to the two reward tasks, only the term for target (free rider or contributor) remained significant (reward judgment: $\beta=4.95,95 \% \mathrm{CI}=[2.99$, 7.88], $O R=141.3$; reward behavior: $\beta=1.42,95 \% \mathrm{CI}=$ $[1.16,1.68])$. There were no significant effects of age (reward judgment: $\beta=1.48,95 \% \mathrm{CI}=[-0.51,4.23]$, $O R=$ 4.40; reward behavior: $\beta=-0.11,95 \% \mathrm{CI}=[-0.60,0.38])$ or condition (reward judgment: $\beta=0.74,95 \% \mathrm{CI}=[-0.45$, 2.07], $O R=2.09$; reward behavior: $\beta=-0.02,95 \% \mathrm{CI}=$ $[-0.27,0.24])$. Children were far more likely to indicate a desire to reward the contributor (95\%) than the free rider (45\%), and children from both age groups gave more candies to contributors $(M=2.28)$ than to free riders ( $M=0.86 ; d=1.50$; Fig. 7$)$. Thus, Study 5 demonstrates that children are willing to inflict punishments and provide rewards to deter free riding and reward contribution, even when such behavior is personally costly.

\section{Combined Analyses for All Five Studies}

Because the design of all five studies was highly similar, as a final step, we aggregated data for all in which an intentional act of free riding occurred and for which we had matched age ranges; we therefore included all data except for the unintentional condition in Studies 1 and 2 and children between the ages of 7 and 8 from Study 1 (because these ages were not included in any other study; a tabular overview of all studies is provided in Table S1 in the Supplemental Material available online). This resulted in a total included sample of 137 participants. We employed a mixed model with responses clustered within participants and to account for potential heterogeneity also clustered by experiment. This constitutes a variant of multilevel metaanalysis, a technique for aggregating results across studies when all data are available (Hox, Moerbeek, \& van de Schoot, 2010). Of primary interest was the aggregated effect of favoring contributors over free riders as well as whether this effect differed as a function of participant age ( $4-5$ years vs. $9-10$ years). This analysis confirmed effects of target $(\beta=2.00,95 \% \mathrm{CI}=[1.78$, $2.21])$ and age $(\beta=0.52,95 \% \mathrm{CI}=[0.29,0.76])$, as well as an interaction between age and target $(\beta=-0.47$, 
Intentional Free Riding No Outcome

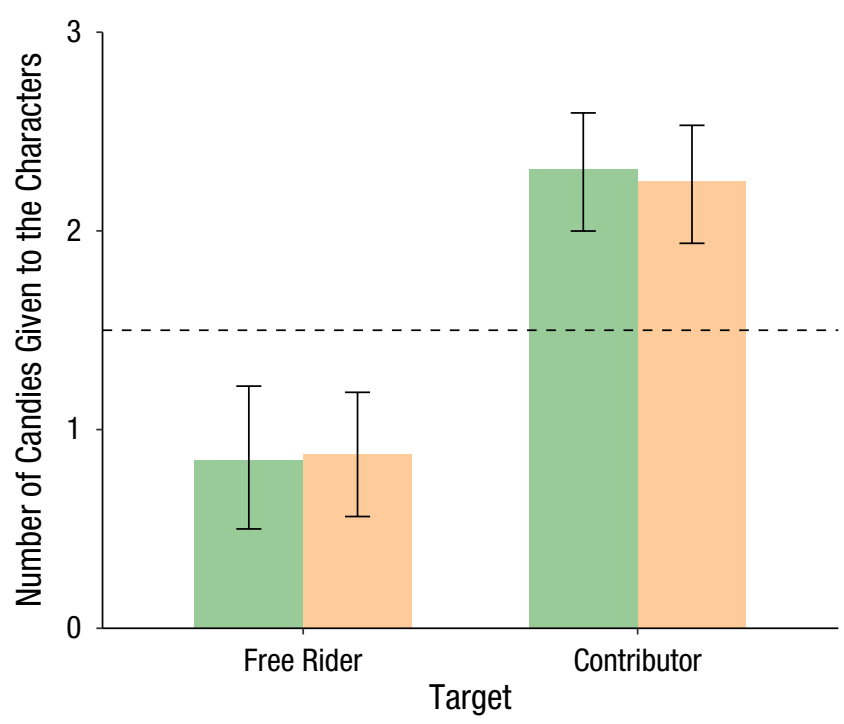

Fig. 7. Number of rewards given to free riders and contributors in the intentional-free-riding and no-outcome conditions of Study 5 (16 children 4-5 years old and 16 children 9-10 years old). Error bars represent bootstrapped $95 \%$ confidence intervals. The dashed line indicates the level of chance response.

95\% CI $=[-0.68,-0.26])$; free riders were evaluated more negatively than contributors by both younger $(d=2.24)$ and older $(d=2.06)$ children in third-party situations, and the overall effect of target across studies was somewhat stronger in younger than older children (see Figure 8).

\section{Study 6}

The prior studies examined children's responses to free riders versus contributors in third-party situations. In Study 6, we examined whether a similar pattern would emerge when children are first parties to the events and so directly experience the free riding of a peer, when their outcomes are and are not affected by the free riding.

\section{Metbod}

Participants. To test emergence in the youngest children examined previously, we focused on 4- to 5-yearolds. To ensure adequate power, we increased the sample size by $50 \%$ compared with previous studies, recruiting 48 participants (mean age $=4.95$ years, $S D=0.57,16$ female), each of whom was randomly assigned to either the impact condition (children's own payoff was affected by the free rider) or the no-impact condition (children's own payoff was not affected by the free rider). The study design and analysis was preregistered at https:// aspredicted.org/h8cy5.pdf.
Procedure. We modeled the first-party scenario after our third-party scenarios, turning it into a game in which the participants believed that they were playing online with three other children connected via video feed. In fact, the roles of the three other children were previously recorded but staged to appear to be occurring simultaneously and interactively. The scenario closely resembled the intentional-free-riding situation used in Studies 1 and 2, in which four children (one of whom was the participant) could choose to donate their own resource (i.e., stickers) to the group and share the group reward later. Thus, participants had the opportunity to donate and then observed two of the other children contributing and one child free riding. In the impact condition, free riding imposed costs on the participant in the form of a smaller group prize (i.e., a page of stickers) at the end, while in the no-impact condition, it did not impose such costs because the larger group prize (i.e., a sticker book) could still be obtained with three contributions. We assessed views of free riders versus contributors by asking children which child (free rider vs. contributor) (a) did a better thing and whether they thought it was "a little better or a lot better" (judgment question; 4-point scale); (b) they liked more, and whether they liked the preferred child "a little more or a lot more" (preference question; 4-point scale); (c) they would like to punish (by taking a sticker away; punishment question; dichotomous); and (d) they would like to work together

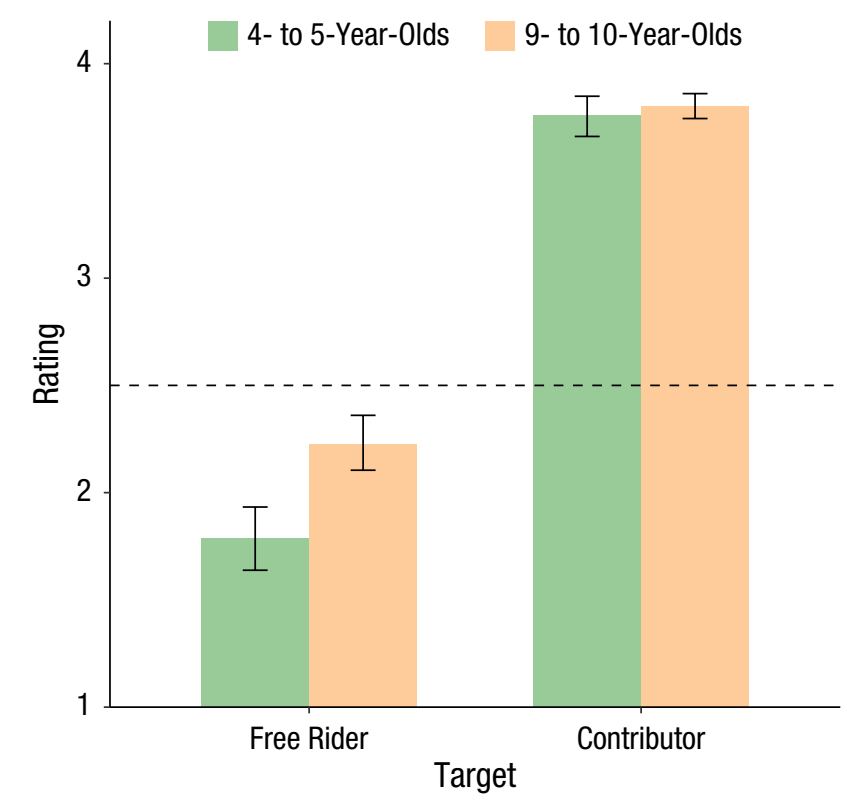

Fig. 8. Summary of aggregated data from Studies 1 to 5 , excluding the unintentional conditions from Studies 1 and $2(N=137)$ : children's evaluations of free riders and contributors, separately for 4- to 5-year-olds and 9- to 10-year-olds. Error bars represent bootstrapped 95\% confidence intervals. On the $y$-axis, 1 equals most negative, and 4 equals most positive. The dashed line indicates the level of chance response. 
with to build a tower (partner-choice question; dichotomous). The use of relative preference measures contrasting the free rider and contributor was a departure from the independent ratings of each target in prior studies. We made this decision because of the possibility that the collaborative context would amplify a sense of community and so lead to generally positive ratings of all targets, including free riders. Given this change, however, the ratings from this study are not directly comparable with those in the prior studies. At the conclusion of the study, we also assessed whether children believed that they had actually been playing together with other children by asking, "Did you play this game alone, or did you play with three other kids as a group?" In the end, we debriefed the children by telling them the game had been pretend and provided all participants with the larger prize.

\section{Results}

The majority of children (90\%) believed that they were playing with other children in the game, suggesting that we successfully created a believable first-party situation.
However, all results reported below are qualitatively the same if we exclude the minority of children who reported that they played the game alone. All participants donated their own sticker and so could be included in a single analysis. As in prior studies, we used children's judgment and preference ratings as indicators for evaluation and fit a linear mixed-effects model using condition (contrast coded; impact vs. no impact) to predict ratings $(1=$ free-rider most positive, $4=$ contributor most positive). We found a significant intercept $(\beta=3.42,95 \% \mathrm{CI}=[3.15,3.69])$, indicating favoritism for the contributor compared with the free rider, but no significant effect of condition $(\beta=-0.38,95 \% \mathrm{CI}=$ [-0.92, 0.17]; Fig. 9a).

For the punishment question, we fitted a logistic model predicting punishment decisions $(0=$ punish free rider, $1=$ punish contributor $)$. There was again no significant effect of condition $(\beta=0.19,95 \% \mathrm{CI}=[-1.03$, $1.44]$ ), but children in both conditions were more likely to punish the free rider than the contributor $(\beta=-0.79$, $95 \% \mathrm{CI}=[-1.43,-0.20], \mathrm{OR}=0.45)$. For the partnerchoice question, we fitted a similar model predicting

\section{a}

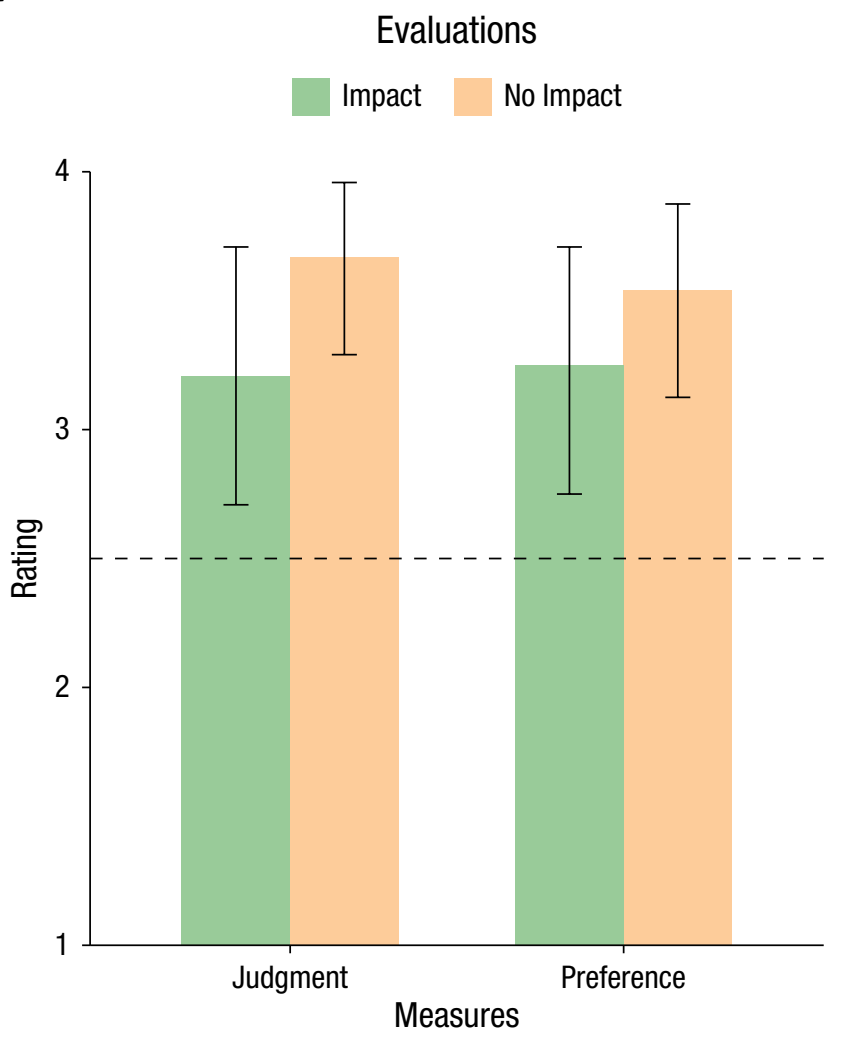

b

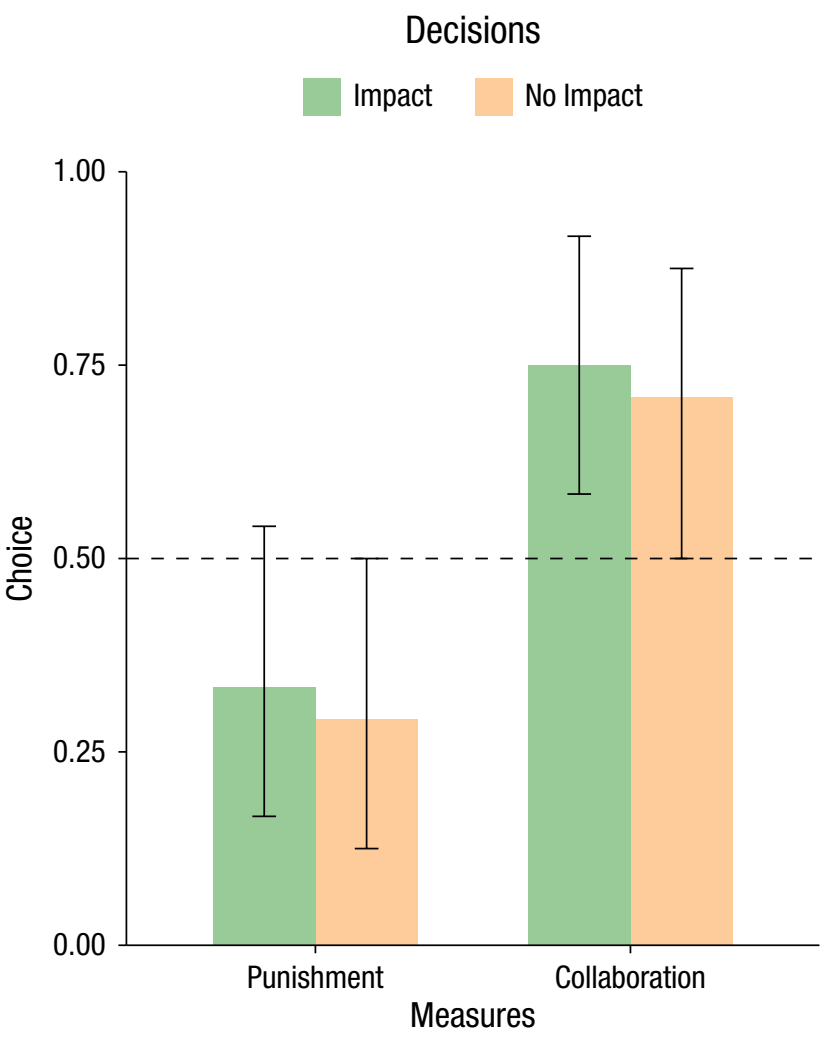

Fig. 9. Children's (a) evaluations and (b) decisions as first-party players in Study 6 when their own payoff was affected (impact condition) and not affected (no-impact condition) by the free rider. Error bars represent bootstrapped $95 \%$ confidence intervals. On the $y$-axes, 1 equals most negative, and 4 equals most positive in (a), and 0 equals free rider and 1 equals contributor in (b). Dashed lines indicate the level of chance response. 
collaboration decisions $(0=$ collaborate with free rider, $1=$ collaborate with contributor). Again, there was no significant effect of condition $(\beta=0.21,95 \% \mathrm{CI}=[-1.07$, $1.52]$ ), but children in both conditions were less willing to collaborate with the free rider than with the cooperator $(\beta=0.99,95 \% \mathrm{CI}=[0.38,1.67], \mathrm{OR}=2.70$; Fig. $9 \mathrm{~b})$. Therefore, our findings demonstrate that young children negatively evaluate, punish, and choose not to collaborate with free riders compared with contributors when they are first parties to the interaction and do so both when their own outcomes are and are not affected.

\section{General Discussion}

Across six studies, we found an early-emerging and sophisticated tendency to negatively evaluate and sanction free riders. Children as young as 4 to 5 years old negatively evaluated, punished, and chose not to reward or collaborate with free riders, across first- and third-party contexts and both when their own outcomes were and were not affected. These findings show that children hold and defend a tacit normative expectation of obligations to the common good, even when these situations involve no visible harm, identifiable victims, unjust rewards, or explicit rules. Thus, children's reactions to free riders are not limited to situations in which their own interests are at stake (Alencar et al., 2008; Harbaugh \& Krause, 2000; Vogelsang et al., 2014), and children's norm understanding and enforcement are not limited to dyadic interactions or violations of explicit moral principles and established rules (Hamlin, Wynn, \& Bloom, 2007; Kenward \& Dahl, 2011; Kenward \& Östh, 2012; Kiley Hamlin, Wynn, \& Bloom, 2010; McAuliffe et al., 2015; Riedl et al., 2015; Rossano et al., 2011; Vaish et al., 2011). The emergence of a normative expectation of group obligation thus constitutes an important advancement in our moral conscience and a critical support for cooperation in groups.

Importantly, our findings reveal that negativity toward free riders arises because of a negative evaluation of free riding per se, rather than because of a number of other factors that frequently co-occur with free riding. In particular, negative evaluations of free riders could not be accounted for by the negative impact free riding can have on group outcomes (Study 3), simple negativity toward nonconformity (Study 4), or the obtaining of undeserved rewards (Study 5). Indeed, even when all outcome information was omitted, children still negatively evaluated and sanctioned noncontributors (Study 5). Thus, our findings suggest that free riding is construed as intrinsically rather than extrinsically blameworthy.

An evolved psychological mechanism for detecting and deterring free riders has been suggested as a potentially important contributor to the stability of cooperation in multiparty settings, and adults' spontaneous detection and negative evaluation of free riders are consistent with this possibility (Delton et al., 2012; Fehr \& Gächter, 2000; Masclet et al., 2003; Price, 2005, 2006a, 2006b; Price et al., 2002). But adults have extensive experience with institutional and other societal sanctions directed at free riders, raising an alternative explanation: Sanctioning free riders is a learned norm. While our results do not settle this issue, they show that the tendency to sanction free riders emerges several years prior to formal schooling, when children are not yet expected to be regular contributors and are unlikely to be sanctioned for failing to contribute themselves. Indeed, for at least two reasons our results are challenging for straightforward socialization accounts. First, in an aggregated analysis of all cases of intentional free riding (drawn from Studies 1-5), we observed greater negativity toward free riders in younger children, a pattern inconsistent with gradual norm internalization. Second, the developmental patterns observed here appear to emerge earlier than other forms of norm enforcement. For example, compared with free riding, unfairness in dyadic interactions presumably occurs more frequently in children's life and thus should be a more direct target for socialization. However, if not directly affected, children do not sanction such violations until middle childhood (McAuliffe et al., 2015). Therefore, our findings suggest that protracted social learning and extensive group experiences are not necessary for the emergence of a tendency to sanction free riders. Our results are consistent with proposals for an evolved psychological machinery for cheater detection and sanctioning.

The primary age-related shift was older children's greater tendency to excuse instances of unintentional free riding, consistent with the suggestion that younger children are more likely to make outcome-oriented moral judgments (Killen et al., 2011; Yuill \& Perner, 1988; Zelazo et al., 1996). It also suggests that children's view of free riding does undergo some developmental refinement, moving from a focus on noncontributing behavior to noncontributing intention. However, children of all ages impose some penalties on unintentional free riders, which may have some advantages, especially in childhood: Behaviors are more observable and objective than intentions and thus are a useful initial cue to the presence of free riding. Integrating intentions becomes more beneficial when predicting whether a noncontributor will cooperate in the future, and this may develop gradually as perspective-taking abilities improve.

In conclusion, our findings demonstrate a strong and early-emerging tendency to negatively evaluate and 
sanction free riders. These reactions are not primarily derived from the immediate consequences to children themselves or to others, but rather appear to reflect a belief that contributing to group activities is an intrinsic moral obligation. Therefore, from early in life, we are blessed with moral tendencies that constitute an important psychological mechanism of facilitating multiparty cooperation and promoting the common good.

\section{Action Editor}

Bill von Hippel served as action editor for this article.

\section{Author Contributions}

F. Yang developed the study concept. All authors contributed to the study design. Testing and data collection were performed by F. Yang and X. Yang. F. Yang and Y. Dunham analyzed the data. F. Yang drafted the manuscript. All authors provided feedback on the manuscript, and Y. Dunham made critical revisions. All the authors approved the final version of the manuscript for submission.

\section{Acknowledgments}

We would like to thank David Rand and Eric Mandelbaum for feedback on a prior version of this article.

\section{Declaration of Conflicting Interests}

The author(s) declared that there were no conflicts of interest with respect to the authorship or the publication of this article.

\section{Funding}

We would like to acknowledge the generous financial support of the John Templeton Foundation and the Happiness and Well-Being Project.

\section{Supplemental Material}

Additional supporting information can be found at http:// journals.sagepub.com/doi/suppl/10.1177/0956797618779061

\section{Open Practices

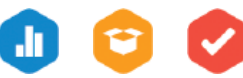

All data and materials have been made publicly available via the Open Science Framework and can be accessed at https:// osf.io/g8xyt/. The design and analysis plans for Studies 3 and 6 were preregistered at AsPredicted (Study 3: https://aspredicted .org/uv6ha.pdf; Study 6: https://aspredicted.org/h8cy5.pdf; note that Study 3 was preregistered as Study 2). The complete Open Practices Disclosure for this article can be found at http://jour nals.sagepub.com/doi/suppl/10.1177/0956797618779061. This article has received badges for Open Data, Open Materials, and Preregistration. More information about the Open Practices badges can be found at http://www.psychologicalscience.org/ publications/badges.

\section{References}

Alencar, A. I., de Oliveira Siqueira, J., \& Yamamoto, M. E. (2008). Does group size matter? Cheating and cooperation in Brazilian school children. Evolution and Human Behavior, 29, 42-48.

Boyd, R., \& Richerson, P. J. (2009). Culture and the evolution of human cooperation. Philosophical Transactions of the Royal Society B: Biological Sciences, 364, 32813288.

Corriveau, K. H., \& Harris, P. L. (2010). Preschoolers (sometimes) defer to the majority in making simple perceptual judgments. Developmental Psychology, 46, 437-445.

Cushman, F., Sheketoff, R., Wharton, S., \& Carey, S. (2013). The development of intent-based moral judgment. Cognition, 127, 6-21.

Delton, A. W., Cosmides, L., Guemo, M., Robertson, T. E., \& Tooby, J. (2012). The psychosemantics of free riding: Dissecting the architecture of a moral concept. Journal of Personality and Social Psychology, 102, 1252-1270.

Fehr, E., \& Fischbacher, U. (2003). The nature of human altruism. Nature, 425, 785-791.

Fehr, E., \& Gächter, S. (2000). Fairness and retaliation: The economics of reciprocity. Journal of Economic Perspectives, 14, 159-181.

Fischbacher, U., Gächter, S., \& Fehr, E. (2001). Are people conditionally cooperative? Evidence from a public goods experiment. Economics Letters, 71, 397-404.

Gray, K., Young, L., \& Waytz, A. (2012). Mind perception is the essence of morality. Psychological Inquiry, 23, 101-124.

Hamlin, J. K., Wynn, K., \& Bloom, P. (2007). Social evaluation by preverbal infants. Nature, 450, 557-559.

Harbaugh, W. T., \& Krause, K. (2000). Children's altruism in public good and dictator experiments. Economic Inquiry, 38, 95-109.

Haun, D., \& Tomasello, M. (2011). Conformity to peer pressure in preschool children. Child Development, 82, 1759-1767.

House, B. R., Silk, J. B., Henrich, J., Barrett, H. C., Scelza, B. A., Boyette, A. H., . . L Laurence, S. (2013). Ontogeny of prosocial behavior across diverse societies. Proceedings of the National Academy of Sciences, USA, 110, 14586-14591.

Hox, J. J., Moerbeek, M., \& van de Schoot, R. (2010). Multilevel analysis: Techniques and applications. New York, NY: Routledge.

Jin, K. S., \& Baillargeon, R. (2017). Infants possess an abstract expectation of ingroup support. Proceedings of the National Academy of Sciences, USA, 114, 81998204.

Jordan, J. J., McAuliffe, K., \& Warneken, F. (2014). Development of in-group favoritism in children's third-party punishment of selfishness. Proceedings of the National Academy of Sciences, USA, 111, 12710-12715.

Kenward, B., \& Dahl, M. (2011). Preschoolers distribute scarce resources according to the moral valence of recipients' previous actions. Developmental Psychology, 47, 10541064.

Kenward, B., \& Östh, T. (2012). Enactment of third-party punishment by 4-year-olds. Frontiers in Psychology, 3, Article 373. doi:10.3389/fpsyg. 2012.00373 
Keser, C., \& Van Winden, F. (2000). Conditional cooperation and voluntary contributions to public goods. The Scandinavian Journal of Economics, 102, 23-39.

Kiley Hamlin, J., Wynn, K., \& Bloom, P. (2010). Three-montholds show a negativity bias in their social evaluations. Developmental Science, 13, 923-929.

Killen, M., Mulvey, K. L., Richardson, C., Jampol, N., \& Woodward, A. (2011). The accidental transgressor: Morally-relevant theory of mind. Cognition, 119, 197-215.

Masclet, D., Noussair, C., Tucker, S., \& Villeval, M.-C. (2003). Monetary and nonmonetary punishment in the voluntary contributions mechanism. American Economic Review, 93, 366-380.

McAuliffe, K., Jordan, J. J., \& Warneken, F. (2015). Costly thirdparty punishment in young children. Cognition, 134, 1-10.

Melis, A. P., Altrichter, K., \& Tomasello, M. (2013). Allocation of resources to collaborators and free-riders in 3-year-olds. Journal of Experimental Child Psychology, 114, 364-370.

Price, M. E. (2005). Punitive sentiment among the Shuar and in industrialized societies: Cross-cultural similarities. Evolution and Human Behavior, 26, 279-287.

Price, M. E. (2006a). Judgments about cooperators and freeriders on a Shuar work team: An evolutionary psychological perspective. Organizational Behavior and Human Decision Processes, 101, 20-35.

Price, M. E. (2006b). Monitoring, reputation, and 'greenbeard' reciprocity in a Shuar work team. Journal of Organizational Behavior, 27, 201-219.

Price, M. E., Cosmides, L., \& Tooby, J. (2002). Punitive sentiment as an anti-free rider psychological device. Evolution and Human Behavior, 23, 203-231.

Rakoczy, H., Brosche, N., Warneken, F., \& Tomasello, M. (2009). Young children's understanding of the context-relativity of normative rules in conventional games. British Journal of Developmental Psychology, 27, 445-456.

Rakoczy, H., Warneken, F., \& Tomasello, M. (2008). The sources of normativity: Young children's awareness of the normative structure of games. Developmental Psychology, $44,875-881$.
Riedl, K., Jensen, K., Call, J., \& Tomasello, M. (2015). Restorative justice in children. Current Biology, 25, 1731-1735.

Rossano, F., Rakoczy, H., \& Tomasello, M. (2011). Young children's understanding of violations of property rights. Cognition, 121, 219-227.

Schmidt, M. F., Rakoczy, H., \& Tomasello, M. (2012). Young children enforce social norms selectively depending on the violator's group affiliation. Cognition, 124, 325-333.

Stoddart, T., \& Turiel, E. (1985). Children's concepts of crossgender activities. Child Development, 56, 1241-1252.

Tooby, J., Cosmides, L., \& Price, M. E. (2006). Cognitive adaptations for $n$-person exchange: The evolutionary roots of organizational behavior. Managerial and Decision Economics, 27, 103-129.

Toomey, R. B., Card, N. A., \& Casper, D. M. (2014). Peers' perceptions of gender nonconformity: Associations with overt and relational peer victimization and aggression in early adolescence. The Journal of Early Adolescence, 34, 463-485.

Vaish, A., Missana, M., \& Tomasello, M. (2011). Three-yearold children intervene in third-party moral transgressions. British Journal of Developmental Psychology, 29, 124-130.

Vogelsang, M., Jensen, K., Kirschner, S., Tennie, C., \& Tomasello, M. (2014). Preschoolers are sensitive to free riding in a public goods game. Frontiers in Psychology, 5, Article 729. doi:10.3389/fpsyg.2014.00729

Walker, M. B., \& Andrade, M. G. (1996). Conformity in the Asch task as a function of age. The Journal of Social Psychology, 136, 367-372.

Wyman, E., Rakoczy, H., \& Tomasello, M. (2009). Normativity and context in young children's pretend play. Cognitive Development, 24, 146-155.

Yuill, N., \& Perner, J. (1988). Intentionality and knowledge in children's judgments of actor's responsibility and recipient's emotional reaction. Developmental Psychology, 24, 358-365.

Zelazo, P. D., Helwig, C. C., \& Lau, A. (1996). Intention, act, and outcome in behavioral prediction and moral judgment. Child Development, 67, 2478-2492. 